\title{
Habitat heterogeneity stabilizes the spatial and temporal interactions between cereal aphids and parasitic wasps
}

\author{
Zi-Hua Zhao ${ }^{\mathrm{a}, *}$, Cang Hui ${ }^{\mathrm{b}, \mathrm{c}}$, Zhi-Hong Li ${ }^{\mathrm{a}}$, Bai-Lian $\mathrm{Li}^{\mathrm{d}}$,e \\ ${ }^{a}$ Department of Entomology, College of Agriculture and biotechnology, China Agricultural University, Beijing \\ 100193, China \\ ${ }^{\mathrm{b}}$ Centre for Invasion Biology, Department of Mathematical Sciences, Stellenbosch University, Matieland 7602, \\ South Africa \\ ${ }^{\mathrm{c}}$ Mathematical and Physical Biosciences, African Institute for Mathematical Sciences, Muizenberg 7945, South \\ Africa \\ ${ }^{\mathrm{d}}$ Ecological Complexity and Modeling Laboratory, Department of Botany and Plant Sciences, University of \\ California, Riverside, CA 92521-0124, USA \\ e USDA-China MOST Joint Research Center for AgroEcology and Sustainability, University of California, Riverside, \\ CA 92521, USA
}

Received 29 May 2014; received in revised form 27 May 2015; accepted 23 June 2015

Available online 30 June 2015

\begin{abstract}
Although it is widely recognized that landscape heterogeneity (LH) can enhance the activity of natural enemies, little is known about the effect of LH on the spatial and temporal stability of pests and their natural enemies. Here, we designed a gradient of LH in agro-ecosystems and examined experimentally the relationship between LH and the spatial and temporal stability of cereal aphids and their parasitic wasps from 2009 to 2012. Stability was measured by the reciprocal of the spatial and temporal coefficients of variation of the population density. Results showed that LH can significantly homogenize the distribution of cereal aphids and their parasitic wasps, thus enhancing the spatial stability of the system. Increasing LH further dampened the fluctuation of the populations of primary parasitoids and hyperparasitoids, thus enhancing the temporal stability of the system. The stability of parasitism and hyperparasitism was also improved with the increase of LH, with the hyperparasitism being more sensitive to the heterogeneity change. Consequently, integrated pest management in agro-ecosystems could be better studied from a multi-trophic food-web perspective.
\end{abstract}

\section{Zusammenfassung}

Während weithin bekannt ist, dass die Landschaftsheterogenität (LH) die Aktivität von natürlichen Feinden steigern kann, ist wenig über den Einfluss der LH auf die räumliche und zeitliche Stabilität von Schadinsekten und ihren Gegenspielern bekannt. Wir entwarfen einen Gradienten der LH in Agrarsystemen und untersuchten experimentell die Beziehung zwischen LH und der räumlichen und zeitlichen Stabilität von Getreideblattläusen und ihren parasitischen Wespen (2009.2012). Die Stabilität wurde gemessen als Kehrwert der räumlichen und zeitlichen Variationskoeffizienten der Populationsdichte. Unsere Ergebnisse

${ }^{*}$ Corresponding author. Tel.: +86010 62733000; fax: +86 01062733000 .

E-mail address: zhzhao@cau.edu.cn (Z.-H. Zhao). 
zeigten, dass LH die Verteilungen der Getreideblattläuse und ihrer Parasitoide signifikant homogenisieren kann, wodurch die räumliche Stabilität des Systems verstärkt wird. Zunehmende LH dämpfte darüber hinaus die Fluktuationen der Populationen von primären Parasitoiden und Hyperparasitoiden, wodurch die zeitliche Stabilität des Systems erhöht wird. Die Stabilität von Parasitierung und Hyperparasitierung wurde ebenfalls mit steigender LH gesteigert, wobei die Hyperparasitierung empfindlicher gegenüber Heterogenitätsänderungen war. Es folgt, dass integriertes Schädlingsmanagement in Agrarökosystemen besser mit einer multitrophischen Nahrungsnetz-Ansatz untersucht werden könnte.

() 2015 Gesellschaft für Ökologie. Published by Elsevier GmbH. All rights reserved.

Keywords: Biological control; Food web; Habitat management; Landscape; Parasitism

\section{Introduction}

The sustainable management of pests at the landscape scale is important for sustaining the yield in agro-ecosystems, where pests and their natural enemies form the key biotic module (Landis, Wratten, \& Gurr 2000; Thies et al. 2011). Understanding how landscape patterns affect species diversity and composition of pests and their natural enemies in agro-ecosystems is a great challenge to sustainable management (Steingrover, Geertsema, \& van Wingerden 2010). The loss of natural enemies and the decline of their biocontrol services have been reported in many ecosystems, with landscape changes recognized as one of the most important drivers (Schmidt et al. 2003; Chaplin-Kramer \& Kremen 2012; Tscharntke et al. 2012). It is, thus, crucial to elucidate how insect communities that provide multiple ecosystem services respond to landscape changes (Werling \& Gratton 2010).

Many studies have examined the relationship between landscape heterogeneity ( $\mathrm{LH})$ and the abundance of natural enemies (Cardinale 2012; Jonsson et al. 2012; Martin, Reineking, Seo, \& Steffan-Dewenter 2013). Changes in LH can drive the rearrangement and redistribution of habitat patches for insects (Thies et al. 2011). Increasing LH has been found, in most cases, to enhance the abundance of natural enemies and suppress pest populations (Meehan, Werling, Landis, \& Gratton 2011; Woltz, Isaacs, \& Landis 2012; Zhao et al. 2013a). Because a parasitic wasp (a bio-control agent) needs to search for different food resources in multiple habitats during its life cycle (Gagic et al. 2011; Rand, van Veen, \& Tscharntke 2012), the bio-control of pests in agro-ecosystems is likely to be affected by land-use changes. Indeed, such changes can affect the availability of surrounding semi-natural habitats to parasitic wasps as alternative food sources and overwintering refuges (Tscharntke et al. 2008; Woltz et al. 2012).

Habitat management of landscape composition and heterogeneity, at both local and regional scales, has been proposed as an important avenue for optimizing bio-control services from natural enemies (Rosch, Tscharntke, Scherber, \& Batary 2013). In particular, increasing LH has been widely recommended in pest management (Batary, Andras, Kleijn, \& Tscharntke 2011; Haddad, Crutsinger, Gross, Haarstad, \&
Tilman 2011). As one way to increase LH, the construction of semi-natural habitats and refuges in agricultural landscapes can be an effective method for boosting the activity and abundance of natural enemies (Steingrover et al. 2010). However, as agricultural pests and their natural enemies are functioning in different modules and at different trophic levels, experiments on how LH affects this agricultural food web warrants investigation.

The diversity of natural enemies in agricultural landscapes is often positively associated with landscape complexity and forms the basis for effective biocontrol (Thies, SteffanDewenter, \& Tscharntke 2008). However, although diversity is largely positively correlated with community-level metrics such as cumulative abundance, it has a rather versatile relationship with population stability, positive in some cases whilst negative in others (Valone \& Hoffman 2003). As the stability of natural enemies can ensure a constant pressure on pests (Tscharntke et al. 2012), biocontrol services and agricultural sustainability can be assured by safeguarding both species diversity and population stability. However, although LH can improve the abundance and diversity of natural enemies by supplying them with abundant food resources and refuges, whether it could also increase the population stability of natural enemies in agroecosystems is largely unknown; consequently its role in the biocontrol of major pests remains unclear (Vollhardt, Tscharntke, Wackers, Bianchi, \& Thies 2008; Gagic et al. 2012).

Ecological stability, including both resistance and resilience, can only be assessed in long-term field experiments (Tilman \& Downing 1994). Resistance is the tolerance of an ecosystem to disturbance while resilience is a measure of the capability of recovering from a disturbance. A common measure of population stability is the reciprocal of the coefficient of variation, which can be calculated using both the temporal series and spatial distributions of population densities (Haddad et al. 2011). The coefficient of variation (CV) measures the variation in the number of individuals across samples (Hui, Veldtman, \& McGeoch 2010) and has been widely used in field studies for reflecting the stability of a focal component in ecosystems (e.g. Tilman, Reich, \& Knops 2006). Other stability measures do exist but we chose the inverse CV due to its simplicity and universality for comparison with literature results. 
Population reflects how population dynamics behave at particular spatial scales and during a certain period. Consequently, population stability is inevitably related to the complexity of ecosystem resources and habitats. As the changes of LH in agro-ecosystems can alter the distribution of plants as resources and habitats, it will affect the food and refuges accessible to insects and thus their population stability. Some studies have speculated that heterogeneous landscapes can improve the population stability of insects due to the buffering effect from enhanced species richness (Haddad et al. 2011; Tscharntke et al., 2012). However, theoretical debates on the processes and mechanisms behind ecosystem complexity and stability have heavily laid on adaptive responses and trait complementarity in ecological networks (e.g. Doebeli \& Ispolatov 2010; Zhang, Hui, \& Terblance 2011). To this end, experimental evidence on how both the stability of different functional modules and their interactions respond to increasing LH in agroecosystems can be valuable for elucidating the extent to which stability is maintained by adaptive responses to complexity changes.

Cereal aphids, their parasitic and hyperparasitic wasps form typical tri-trophic systems (Gagic et al. 2012; Zhao, He, \& Hui 2012). Changing LH can shift the biomass distribution and species composition in these tri-trophic systems, interfering with the biocontrol and even reducing crop yield (Gardiner et al. 2010). What remains unclear is whether LH will stabilize or destabilize the system. Here, we provide evidence of the stabilizing effect of $\mathrm{LH}$ on population dynamics across multiple trophic levels. Specifically, we address two questions: (i) whether increasing LH can enhance the spatial and temporal stability of population density for cereal aphids and their parasitic wasps; (ii) whether increasing LH further stabilizes the interactions between cereal aphids and their parasitic wasps; that is, the rate of parasitism and hyperparasitism in wheat fields.

\section{Materials and methods}

\section{The study area}

The experiment was conducted in Yinchuan, a city at the Ningxia Hui Autonomous Region of Northwest China. In the past few decades, this agricultural region has experienced a gradual landscape change due to agricultural intensification and accompanied simplification. The fragmented semi-natural habitats and the arable field patches form the regional landscape mosaic. Although crop rotation in the agricultural landscape happens annually, the spatial configuration of semi-natural habitats and arable lands remains relatively unchanged. Main types of semi-natural habitats include permanent grasslands, fallow lands, woodland and wetland, while wheat, corn, soybean and nuts are the most important regional crop species. We selected wheat fields as our focal habitat.
Twenty-three landscape sites were randomly selected, forming a gradient from structurally simple landscapes with a low proportion of semi-natural lands (10.7\% semi-natural habitats) to structurally complex landscapes with a high proportion of semi-natural habitats (60.4\% semi-natural habitats). In our experiment, the planting time of wheat crop and agricultural management practices were kept the same in all sampling fields to neutralize stochastic disturbances in the various landscape sites. Agrochemicals, including insecticides and herbicides, were not applied to the sites during the whole growth season of wheat (from March to June).

Remote sensing images of nine land cover types within a $500 \mathrm{~m}$ radius to the landscape centre were obtained from Ningxia Research Academy of Environmental Sciences and then used for calculating the LH, using the Patch Analyst extension of FRAGSTATS. The nearest neighbor distance among these sites ranges from 1000 to $1800 \mathrm{~m}$. This radius of $500 \mathrm{~m}$ has been regarded as an appropriate spatial scale for analyzing the relationship between the landscape pattern and population dynamics of agricultural insects (Maisonhaute, Peres-Neto, \& Lucas 2010; Stutz \& Entling 2011; Zhao et al. 2013a; Thies, Roschewitz, \& Tscharntke 2005).

\section{Metrics of landscape heterogeneity}

LH can be measured by many metrics that consider landscape diversity, richness, connectivity, and concentration. Here, LH was calculated by the patch mosaic index, proposed by Romme (1982) and Li (1989). This index has been widely applied for depicting landscape structure and proved an appropriate metric of LH especially in agro-ecosystems (Romme 1982; Li 1989). This LH can be calculated as follows,

$$
L H=\frac{1}{N_{\mathrm{a}}} \sum_{i=1}^{s} \sum_{j=1}^{s} E E(i, j) D D(i, j),
$$

where $s$ is the total number of patches in the landscape; $N_{\mathrm{a}}$ is the total length of boundaries between all adjacent patches (measuring habitat interference); $E E(i, j)$ is the nearest distance between patch $i$ and $j ; D D(i, j)$ is the difference of habitat types between patch $i$ and $j$. If patch $i$ and $j$ belong to the same habitat type, the difference was set to 0 . If patch $i$ and $j$ belong to different habitat types (e.g. grassland vs. forest), the differences was set to 1 . The identification of habitat type (land cover) and estimates of $D D(i, j)$ were conducted through monitoring classification in GIS (Turner, O'Neill, Gardner, \& Milne 1989; Gustafson 1998).

\section{Insect sampling}

Cereal aphids and their parasitic wasps were sampled seven times per year in the wheat growing season from 15 April to 10 July in 2009-2012 by both visual observation and hand collection (Schmidt, Thies, Nentwig, \& Tscharntke 2008; Zhao, Shi, Men, Ouyang, \& Ge 2013b). In each site, three 
wheat fields were selected randomly to conduct the insect sampling. Therefore, 69 wheat fields $(23 \times 3)$ were selected in the experiment. Insect samples were collected twice per month from five randomly selected spots per wheat field. At each spot, 100 tillers of wheat crop were selected randomly for screening; these tillers were selected to be more than $20 \mathrm{~m}$ away from wheat field edges to avoid potential spillover and edge effects.

Both live and mummy cereal aphids were gathered simultaneously and taken to the laboratory for rearing of adult parasitoids. All field-collected mummies were stored individually in gelatin capsules until the emergence of adult parasitic wasps. The rearing condition was maintained at $20{ }^{\circ} \mathrm{C}$ with $14: 10$ light, with a damp cotton plug added to the tube to keep the humidity constant. The mummy was examined twice daily for the first month for wasp emergence, and then once every 2 days in the following month. Aphids that died during the rearing period were dissected to check for parasitism. In each trophic group, we selected two dominant species which accounted for $>85 \%$ of individuals in the experiment. Six dominant species, including aphids (Sitobion avenae and Schizaphis graminum, accounting for $91 \%$ of aphids), primary parasitoids (Aphidius avenae and A. gifuensis, accounting for $96 \%$ of primary parasitoids), and hyperparasitoids (Asaphes suspensus and Pachyneuron aphidis, accounting for $76 \%$ of hyperparasitoids), were selected for further analyses.

\section{Statistical analyses}

Population densities of cereal aphids and their parasitic wasps were calculated as individuals/100 tillers. Spatial Moran's I statistics were used for measuring the spatial autocorrelation of population densities in different wheat fields. As no significant spatial autocorrelation was detected for any species in this experiment, it was not considered in further analyses. The stability of cereal aphids and their parasitic wasps was calculated in terms of spatial and temporal variability. The reciprocal of the coefficient of variation $(1 / \mathrm{CV})$ of the population density was used as the stability index (Haddad et al. 2011), where CV equals the standard deviation divided by the means. The population-level $\mathrm{CV}$ was calculated on two levels: the spatial CV within a wheat field and the temporal $\mathrm{CV}$ over a period. The spatial $\mathrm{CV}$ was calculated as the variation of population density among five spots in each wheat field (Haddad et al. 2011) while the temporal CV was calculated as the variation of the average population density of these 5 spots for seven sampling times within a year.

A nested analysis was conducted using a generalized linear mixed model (GLMM) with the restricted maximum likelihood method, which was then used for assessing the effect of LH, wheat field, and year on the spatial/temporal stability of cereal aphids and their parasitic wasps (Peralts, Frost, Rand, Didhan, \& Tylianakis 2014). We considered "wheat fields" as a random factor nested within 'Landscape site' since three wheat fields were selected in each site and the extent of stability might be partially correlated. 'Years' was also considered as a random factor due to the four-year duration of this study. LH and population stability with a binomial error distribution were regarded as independent and dependent variables, respectively.

We found that two random factors (wheat field and year) did not significantly affect the stability of cereal aphids and parasitic wasp with only a few exceptions. Consequently, a simple linear regression model was used for fitting the relationship between $\mathrm{LH}$ and the spatial/temporal stability of cereal aphids and their parasitic wasps. The same GLMM and linear regression were also used for assessing the relationship between LH and the stability of primary parasitism and hyperparasitism. All analyses were performed in R 2.15.1 (R Development Core Team 2012).

\section{Results}

The within-year population dynamics of cereal aphids followed a unimodal curve from 2009 to 2012 (Fig. 1). The population density of cereal aphids peaked in late May and declined abruptly in mid-June. The densities of primary parasitoids and hyperparasitoids peaked in late June, closely following the peak of cereal aphids. However, primary parasitism and hyperparasitsm increased continuously from May to early July, following an exponential growth (Fig. A1).

LH had a significant effect on the spatial stability of cereal aphids and their parasitic wasps. Of the two cereal aphid species, increasing LH had a significantly positive effect on the spatial stability of Sitobion avenae, while year and wheat field exerted no noticeable effects. In contrast, the spatial stability of Schizaphis graminum was significantly affected by LH, year, and wheat fields (Table 1). Furthermore, increasing LH also significantly enhanced the spatial stability of the selected dominant primary parasitoid species (Aphidius avenae and A. gifuensis), with no effects detected for different years and wheat fields. For the hyperparasitoid group, only LH had a significant effect on the spatial stability of the two dominant species A. suspensus and Pachyneuron aphidis, while year and wheat field were found to have no effect (Table 1). Therefore, a high level of LH is an important stabilizer of the spatial distributions of cereal aphids (Fig. 2A), primary parasitoids (Fig. 2B), and hyperparasitoids (Fig. 2C). The relationship between spatial stability and LH can be described by a linear regression, which indicates higher trophic level species (wasps) were more sensitive to the change in LH than lower trophic level species (cereal aphids) due to the higher regression coefficient (Table 1, Table A1, Fig. 2A-C).

LH also had significant effects on the temporal stability of cereal aphids and their parasitic wasps (Table 1). In addition, the temporal stability of one primary parasitoid (A. gifuensis) and one hyperparasitoid ( $P$. aphidis) differed significant among years. No effect of wheat fields on temporal stability 

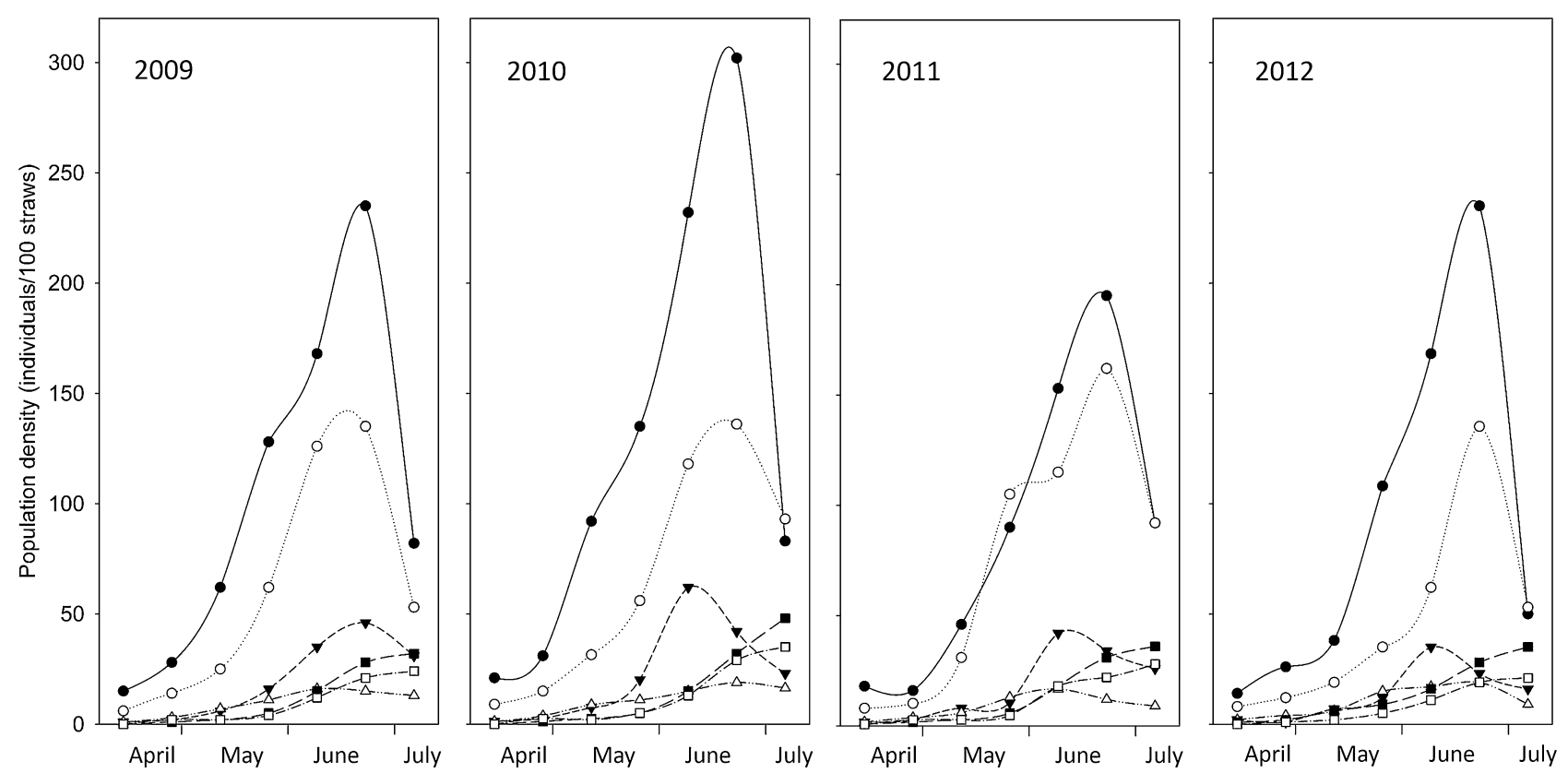

Fig. 1. Population dynamics of cereal aphids (, Sitobion avenae; $\bigcirc$, Schizaphis graminum), primary parasitoids ( $\mathbf{\nabla}$, Aphidius avenae; $\triangle$, Aphidius gifuensis), and hyperparasitoids ( $\mathbf{\square}$, Asaphes suspensus; $\square$, Pachyneuron aphidis) from 2009 to 2012 in the study wheat fields.

Table 1. Nested analysis of the effects of year, wheat field, and landscape heterogeneity (LH) on the spatial and temporal stability of cereal aphids and their parasitic wasps.

\begin{tabular}{|c|c|c|c|c|c|c|}
\hline \multirow[t]{2}{*}{ Species } & \multicolumn{3}{|c|}{ Spatial stability } & \multicolumn{3}{|c|}{ Temporal stability } \\
\hline & $P_{\text {year }}$ & $P_{\text {wheat field }}$ & $P_{\mathrm{LH}}$ & $P_{\text {year }}$ & $P_{\text {wheat field }}$ & $P_{\mathrm{LH}}$ \\
\hline \multicolumn{7}{|l|}{ Cereal aphid $(\mathrm{df}=3,273)$} \\
\hline Sitobion avenae & 0.598 & 0.920 & $<0.001$ & 0.423 & 0.760 & $<0.001$ \\
\hline Schizaphis graminum & $<0.001$ & 0.001 & $<0.001$ & 0.301 & 0.394 & $<0.001$ \\
\hline \multicolumn{7}{|c|}{ Primary parasitoid $(\mathrm{df}=3,273)$} \\
\hline Aphidius avenae & 0.177 & 0.775 & $<0.001$ & 0.699 & 0.031 & $<0.001$ \\
\hline Aphidius gifuensis & 0.458 & 0.435 & $<0.001$ & 0.003 & 0.193 & $<0.001$ \\
\hline \multicolumn{7}{|c|}{ Hyperparasitoid $(\mathrm{df}=3,273)$} \\
\hline Asaphes suspensus & 0.141 & 0.025 & 0.002 & 0.441 & 0.002 & $<0.001$ \\
\hline Pachyneuron aphidis & 0.357 & 0.926 & 0.006 & 0.001 & 0.864 & $<0.001$ \\
\hline \multicolumn{7}{|c|}{ Primary parasitism and hyperparasitism $(\mathrm{df}=3,273)$} \\
\hline Primary parasitism & 0.794 & 0.601 & $<0.001$ & 0.791 & 0.727 & $<0.001$ \\
\hline Hyperparastism & 0.001 & 0.001 & $<0.001$ & 0.507 & 0.217 & $<0.001$ \\
\hline
\end{tabular}

was detected. Although no clear trends were observed across trophic levels (Table 1), the regression coefficients of cereal aphids and parasitic wasps against LH still largely increased with the trophic level (Table A2, Fig. 2D-F).

LH had significant effects on the spatial and temporal stability of primary parasitism which was not different among years and wheat fields. In contrast, year and wheat field had significant effects on the spatial stability of hyperparasitism but no effects on its temporal stability (Table 1). Both the spatial and temporal stability of primary parasitism and hyperparasitism increased significantly with increasing LH, with hyperparasitism being more sensitive than primary parasitism to the increase of LH in agroecosystems (Table A3, Fig. 3A and B).

\section{Discussion}

We found that increasing LH significantly enhanced the population stability across all three trophic levels. As to stabilizing the temporal dynamics of arthropods by increasing $\mathrm{LH}$, we speculate about the following tentative explanations. Most parasitic wasps and aphid predators are anholocyclic species and need alternate aphid hosts after crop harvest (Landis et al. 2000; Schmidt-Entling \& Dobeli 2009). The diverse plant resources could supply complementary food and habitats for these natural enemy populations especially immediately after the harvest, reducing potential population fluctuations. Consequently, increasing LH stabilizes the population dynamics of natural enemies and can be considered 

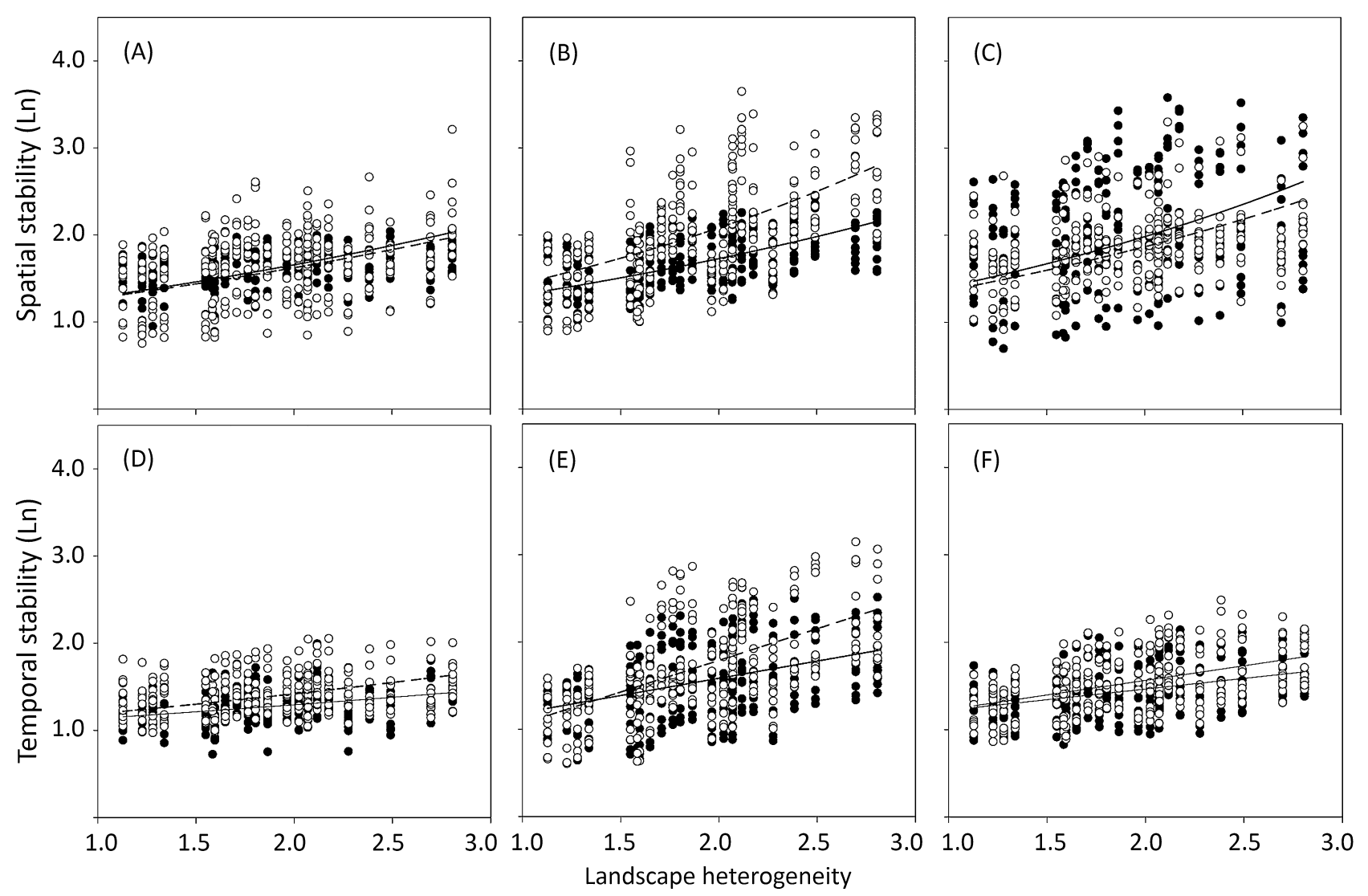

Fig. 2. Effects of increasing landscape heterogeneity (LH) on the spatial and temporal stability (measured as $1 / \mathrm{CV}$ per 100 tillers) of cereal aphids (A and D, solid lines and filled symbols represent $S$. avenae, while dashed lines and open symbols indicate $S$. graminum), primary parasitoids (B and E, solid lines and filled symbols represent A. avenae, while dashed lines and open symbols indicate A. gifuensis), and hyperparasitoids ( $\mathrm{C}$ and $\mathrm{F}$, solid lines and filled symbols represent $A$. suspensus, while dashed lines and open symbols indicate $P$. aphidis) in the agro-ecosystem.

an important mechanism to safeguard biocontrol services in agroecosystems.

As to stabilizing the spatial distributions of arthropods by increasing $\mathrm{LH}$, we speculate the following tentative explanations. The high species richness in a heterogeneous landscape could increase the complexity of food web structures, which may then stabilize the arthropod community (Rand \& Tscharntke 2007; Rand et al. 2012). Heterogeneous landscapes could provide many important physiological and ecological opportunities for spreading, foraging, mating, colonization, breeding, and overwintering shelter for cereal aphids and their parasitic wasps, smoothing out or buffering the spatial variation of population densities (van Veen, Morris, \& Godfray 2006; Lindborg et al. 2008; Gardiner et al. 2009). Consequently, both the spatial and temporal stability of agricultural insects could be strongly enhanced by the bottom-up effects of the abundant alternative habitats in a heterogeneous landscape (Montoya, Rodriguez, \& Hawkins 2003; Holzschuh, Steffan-Dewenter, \& Tscharntke 2010). The high stability of insects could then be beneficial to sustainable biocontrol of pests in agro-ecosystems (Haddad et al. 2011). This agrees with the diversity-stability hypothesis, or at least one side of the debate, which suggest that high biodiversity entails high stability of ecological function such as biocontrol (Tilman et al. 2006).

Our results further suggest that the influence of increasing LH on population stability tends to be stronger when moving up one trophic level from aphids to primary parasitoids, but not so when moving up from primary parasitoids to the even higher trophic level of hyperparasitoids. This contrast can be understood in two ways. First, LH may facilitate both cereal aphids and parasitic wasps, but with the latter more sensitive to increasing LH (Thies et al. 2005; Plecas et al. 2014). Indeed, species at higher trophic levels in general have more diverse diets and wider niches than those at lower trophic levels. The larvae of parasitic wasps feed on pest arthropods, while the adult wasps search for nectar in different habitats. In contrast, cereal aphids can simply complete their life cycle on wheat plants. Therefore, increasing LH, by providing complementary food resources and habitat niches, could facilitate species at higher trophic levels (e.g. parasitic wasps) much more than those at lower trophic levels (e.g. aphids), thus increasing the strength of the aphid-wasp interactions (Gagic et al. 2011; Kleijn, Rundlof, Scheper, Smith, $\&$ Tscharntke 2011) and the efficiency of biocontrol (Jonsson et al. 2012). 

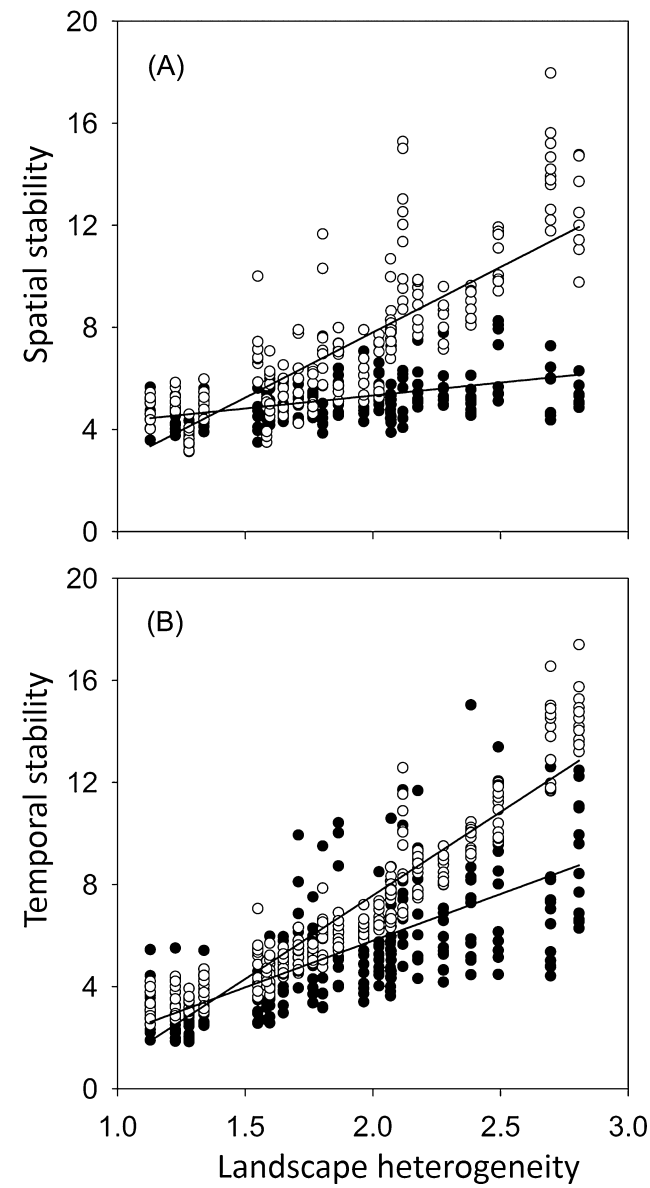

Fig. 3. The relationship between landscape heterogeneity (LH) and the stability of primary parasitism (filled symbols) and hyperparasitism (open symbols) in wheat fields.

Second, the influence of increasing LH on population stability did not increase further to the third trophic level of hyperparasitoids when compared with the influence on the second trophic level of primary parasitoids. This is because most hyperparasitoids have broader host ranges, such as Pachyneuron aphidis (Bouche), which feed on primary parasitoids from multiple habitats (Rand et al. 2012). The broad host range of hyperparasitoids can neutralize the effects of LH due to Jensen's inequality (Müller, Adriaanse, Belshaw, \& Godfray 1999).

Increasing LH was also found to significantly increase the stability of biotic interactions (i.e. parasitism and hyperparasitism). The increasing population stability of cereal aphids and parasitic wasps provides an obvious explanation for the steady biotic interactions in wheat fields, and the results are also consistent with the argument that increasing the stability of biotic interactions in agro-ecosystems can ensure the agricultural sustainability (Thies et al. 2005; Rand et al. 2012).

In conclusion, not only can increasing LH stabilize the population density of parasitic wasps through providing complementary food resources and alternative hosts (Bianchi,
Booij, \& Tscharntke 2006; Batary, Matthiesen, \& Tscharntke 2010; Diehl, Mader, Wolters, \& Birkhofer 2013), but it also facilitates stable biotic interactions (i.e. parasitism) among cereal aphids, primary parasitoids and hyperparasitoids, enhancing the connectivity and stability of arthropod food webs (Tscharntke \& Tylianakis 2010). To this end, LH may act as the key driving force in connecting food webs across multiple habitat patches and trophic levels in agricultural landscapes (Gagic et al. 2011). As the parasitic wasps were more sensitive to the change of LH than their host aphids, LH can be used as a tool to disproportionally affect high-trophic and specialist species which are often crucial for sustainable management of agricultural pests (Bianchi et al. 2006). Pest management could be better studied from a multitrophic food-web perspective in future research (Tscharntke et al. 2012).

\section{Acknowledgments}

We thank Yingshu Zhao, Tingting Zhang, Jia Hang, and Ying Wang for assistance in field investigation. We also thank Prof. Feng Ge and three anonymous reviewers for providing invaluable comments on an earlier draft of this manuscript. This research was funded by National Natural Science Foundation of China (no. 31400349). CH is supported by the National Research Foundation of South Africa (nos. 89967, 81825 and 76912).

\section{Appendix A. Supplementary data}

Supplementary data associated with this article can be found, in the online version, at http://dx.doi.org/10.1016/ j.baae.2015.06.002.

\section{References}

Batary, P., Andras, B., Kleijn, D., \& Tscharntke, T. (2011). Landscape-moderated biodiversity effects of agri-environmental management: A meta-analysis. Proceedings of the Royal Society B-Biological Sciences, 278, 1894-1902.

Batary, P., Matthiesen, T., \& Tscharntke, T. (2010). Landscapemoderated importance of hedges in conserving farmland bird diversity of organic vs. conventional croplands and grasslands. Biological Conservation, 143, 2020-2027.

Bianchi, F. J. J. A., Booij, C. J. H., \& Tscharntke, T. (2006). Sustainable pest regulation in agricultural landscapes: A review on landscape composition, biodiversity and natural pest control. Proceedings of the Royal Society B-Biological Sciences, 273, 1715-1727.

Cardinale, B. J. (2012). Biodiversity loss and its impact on humanity. Nature, 489, 326-L.

Chaplin-Kramer, R., \& Kremen, C. (2012). Pest control experiments show benefits of complexity at landscape and local scales. Ecological Applications, 22, 1936-1948. 
Diehl, E., Mader, V. L., Wolters, V., \& Birkhofer, K. (2013). Management intensity and vegetation complexity affect web-building spiders and their prey. Oecologia, 173, 579-589.

Doebeli, M., \& Ispolatov, I. (2010). Complexity and diversity. Science, 328, 494-497.

Gagic, V., Hanke, S., Thies, C., Scherber, C., Tomanovic, Z., \& Tscharntke, T. (2012). Agricultural intensification and cereal aphid-parasitoid-hyperparasitoid food webs: Network complexity, temporal variability and parasitism rates. Oecologia, 170, 1099-1109.

Gagic, V., Tscharntke, T., Dormann, C. F., Gruber, B., Wilstermann, A., \& Thies, C. (2011). Food web structure and biocontrol in a four-trophic level system across a landscape complexity gradient. Proceedings of the Royal Society B-Biological Sciences, 278, 2946-2953.

Gardiner, M. M., Landis, D. A., Gratton, C., DiFonzo, C. D., O’Neal, M., Chacon, J. M., et al. (2009). Landscape diversity enhances biological control of an introduced crop pest in the north-central USA. Ecological Applications, 19, 143-154.

Gardiner, M. M., Landis, D. A., Gratton, C., Schmidt, N., O’Neal, M., Mueller, E., et al. (2010). Landscape composition influences the activity density of Carabidae and Arachnida in soybean fields. Biological Control, 55, 11-19.

Gustafson, E. J. (1998). Quantifying landscape spatial pattern: What is the state of the art? Ecosystems, 1, 143-156.

Haddad, N. M., Crutsinger, G. M., Gross, K., Haarstad, J., \& Tilman, D. (2011). Plant diversity and the stability of foodwebs. Ecology Letters, 14, 42-46.

Holzschuh, A., Steffan-Dewenter, I., \& Tscharntke, T. (2010). How do landscape composition and configuration, organic farming and fallow strips affect the diversity of bees, wasps and their parasitoids? Journal of Animal Ecology, 79, 491-500.

Hui, C., Veldtman, R., \& McGeoch, M. A. (2010). Measures, perceptions and scaling patterns of aggregated species distributions. Ecography, 33, 95-102.

Jonsson, M., Buckley, H. L., Case, B. S., Wratten, S. D., Hale, R. J., \& Didham, R. K. (2012). Agricultural intensification drives landscape-context effects on host-parasitoid interactions in agroecosystems. Journal of Applied Ecology, 49, 706-714.

Kleijn, D., Rundlof, M., Scheper, J., Smith, H. G., \& Tscharntke, T. (2011). Does conservation on farmland contribute to halting the biodiversity decline? Trends in Ecology \& Evolution, 26, 474-481.

Landis, D. A., Wratten, S. D., \& Gurr, G. M. (2000). Habitat management to conserve natural enemies of arthropod pests in agriculture. Annual Review of Entomology, 45, 175-201.

Li, H. (1989). Spatio-temporal pattern analysis of managed forest landscapes: A simulation approach. Corvallis, OR: Oregon State University. Dissertation

Lindborg, R., Bengtsson, J., Berg, A., Cousins, S. A. O., Eriksson, O., Gustafsson, T., et al. (2008). A landscape perspective on conservation of semi-natural grasslands. Agriculture Ecosystems \& Environment, 125, 213-222.

Maisonhaute, J. E., Peres-Neto, P., \& Lucas, E. (2010). Influence of agronomic practices, local environment and landscape structure on predatory beetle assemblage. Agriculture Ecosystems \& Environment, 139, 500-507.

Martin, E. A., Reineking, B., Seo, B., \& Steffan-Dewenter, I. (2013). Natural enemy interactions constrain pest control in complex agricultural landscapes. Proceedings of the National Academy of Sciences of the United States of America, 110, 5534-5539.
Meehan, T. D., Werling, B. P., Landis, D. A., \& Gratton, C. (2011). Agricultural landscape simplification and insecticide use in the Midwestern United States. Proceedings of the National Academy of Sciences of the United States of America, 108, 11500-11505.

Montoya, J. M., Rodriguez, M. A., \& Hawkins, B. A. (2003). Food web complexity and higher-level ecosystem services. Ecology Letters, 6, 587-593.

Müller, C. B., Adriaanse, I. C. T., Belshaw, R., \& Godfray, H. C. J. (1999). The structure of an aphid-parasitoid community. Journal of Animal Ecology, 68, 346-370.

Peralts, G., Frost, C. M., Rand, T. A., Didhan, R. K., \& Tylianakis, J. M. (2014). Complementarity and redundancy of interactions enhance attack rates and spatial stability in host-parasitoid food webs. Ecology, 95, 1888-1896.

Plecas, M., Gagic, V., Jankovic, M., Petrovic-Obradovic, O., Kavallieratos, N. G., Tomanovic, Z., et al. (2014). Landscape composition and configuration influence cereal aphid-parasitoid-hyperparasitoid interactions and biological control differentially across years. Agriculture Ecosystems \& Environment, 183, 1-10.

R Development Core Team. (2012). R: A language and environment for statistical computing, version 2.15.1. Vienna, Austria: Foundation for Statistical Computing. See 〈http://www.Rproject.org .

Rand, T. A., \& Tscharntke, T. (2007). Contrasting effects of natural habitat loss on generalist and specialist aphid natural enemies. Oikos, 116, 1353-1362.

Rand, T. A., van Veen, F. J. F., \& Tscharntke, T. (2012). Landscape complexity differentially benefits generalized fourth, over specialized third, trophic level natural enemies. Ecography, 35, 97-104.

Romme, W. H. (1982). Fire and landscape diversity in subalpine forests of Yellowstone-National-Park. Ecological Monograph, 52, 199-221.

Rosch, V., Tscharntke, T., Scherber, C., \& Batary, P. (2013). Landscape composition, connectivity and fragment size drive effects of grassland fragmentation on insect communities. Journal of Applied Ecology, 50, 387-394.

Schmidt-Entling, M. H., \& Dobeli, J. (2009). Sown wildflower areas to enhance spiders in arable fields. Agriculture Ecosystems \& Environment, 133, 19-22.

Schmidt, M. H., Lauer, A., Purtauf, T., Thies, C., Schaefer, M., \& Tscharntke, T. (2003). Relative importance of predators and parasitoids for cereal aphid control. Proceedings of the Royal Society B-Biological Sciences, 270, 1905-1909.

Schmidt, M. H., Thies, C., Nentwig, W., \& Tscharntke, T. (2008). Contrasting responses of arable spiders to the landscape matrix at different spatial scales. Journal of Biogeography, 35, 157-166.

Steingrover, E. G., Geertsema, W., \& van Wingerden, W. K. R. E. (2010). Designing agricultural landscapes for natural pest control: A transdisciplinary approach in the Hoeksche Waard (The Netherlands). Landscape Ecology, 25, 825-838.

Stutz, S., \& Entling, M. H. (2011). Effects of the landscape context on aphid-ant-predator interactions on cherry trees. Biological Control, 57, 37-43.

Thies, C., Roschewitz, I., \& Tscharntke, T. (2005). The landscape context of cereal aphid-parasitoid interactions. Proceedings of the Royal Society B-Biological Sciences, 272, 203-210.

Thies, C., Steffan-Dewenter, I., \& Tscharntke, T. (2008). Interannual landscape changes influence plant-herbivore-parasitoid interactions. Agriculture Ecosystems \& Environment, 125, 266-268. 
Thies, C., Haenke, S., Scherber, C., Bengtsson, J., Bommarco, R., Clement, L. W., Ceryngier, P., et al. (2011). The relationship between agricultural intensification and biological control: Experimental tests across Europe. Ecological Applications, 21, 2187-2196.

Tilman, D., \& Downing, J. A. (1994). Biodiversity and stability in grasslands. Nature, 367, 363-365.

Tilman, D., Reich, P. B., \& Knops, J. M. H. (2006). Biodiversity and ecosystem stability in a decadelong grassland experiment. Nature, 441, 629-632.

Tscharntke, T., Bommarco, R., Clough, Y., Crist, T. O., Kleijn, D., Rand, T. A., et al. (2008). Conservation biological control and enemy diversity on a landscape scale. Biological Control, 45, 238-253.

Tscharntke, T., \& Tylianakis, J. (2010). Conserving complexity: Global change and community-scale interactions. Biological Conservation, 143, 2249-2250.

Tscharntke, T., Tylianakis, J. M., Rand, T. A., Didham, R. K., Fahrig, L., Batary, P., et al. (2012). Landscape moderation of biodiversity patterns and processes-eight hypotheses. Biological Reviews, 87, 661-685.

Turner, M. G., O’Neill, R. V., Gardner, R. H., \& Milne, B. T. (1989). Effects of changing spatial scale on the analysis of landscape pattern. Landscape Ecology, 3, 153-162.

van Veen, F. J. F., Morris, R. J., \& Godfray, H. C. J. (2006). Apparent competition, quantitative food webs, and the structure of phytophagous insect communities. Annual Review of Entomology, 51, 187-208.
Vollhardt, I. M. G., Tscharntke, T., Wackers, F. L., Bianchi, F. J. J. A., \& Thies, C. (2008). Diversity of cereal aphid parasitoids in simple and complex landscapes. Agriculture Ecosystems \& Environment, 126, 289-292.

Valone, T. J., \& Hoffman, C. D. (2003). Population stability is higher in more diverse annual plant communities. Ecology Letters, 6 , 90-95.

Werling, B. P., \& Gratton, C. (2010). Local and broadscale landscape structure differentially impact predation of two potato pests. Ecological Applications, 20, 1114-1125.

Woltz, J. M., Isaacs, R., \& Landis, D. A. (2012). Landscape structure and habitat management differentially influence insect natural enemies in an agricultural landscape. Agriculture Ecosystems \& Environment, 152, 40-49.

Zhang, F., Hui, C., \& Terblance, J. S. (2011). An interaction switch predicts the nested architecture of mutualistic networks. Ecology Letters, 14, 797-803.

Zhao, Z. H., He, D. H., \& Hui, C. (2012). From the inverse density-area relationship to the minimum patch size of a host-parasitoid system. Ecological Research, 27, 303-309.

Zhao, Z. H., Hui, C., Ouyang, F., Liu, J. H., Guan, X. Q., He, D. H., et al. (2013). Effects of inter-annual landscape change on interactions between cereal aphids and their natural enemies. Basic and Applied Ecology, 14, 472-479.

Zhao, Z. H., Shi, P. J., Men, X. Y., Ouyang, F., \& Ge, F. (2013). Effects of crop species richness on pest-natural enemy systems based on an experimental model system using a microlandscape. Science China-Life Sciences, 56, 758-766.

Available online at www.sciencedirect.com 